\title{
Multi-male captive groups of endangered dama gazelle: social rank, aggression, and enclosure effects
}

\author{
Jorge Cassinello $^{1,2}$ and Irma Pieters ${ }^{3}$ \\ 1Estación Experimental de Zonas Aridas, CSIC \\ C/General Segura 1, 04001-Almería (Spain) \\ ${ }^{2}$ Departamento de Ecología Evolutiva \\ Museo Nacional de Ciencias Naturales, CSIC \\ C/José Gutiérrez Abascal 2, 28006-Madrid (Spain) \\ 3Van Hall Instituut, P.O. Box 1528 \\ 8901 Leeuwarden (The Netherlands)
}

Short title: Multi-male groups of dama gazelles

Correspondence should be addressed to:

J. Cassinello

Museo Nacional de Ciencias Naturales, CSIC

C/José Gutiérrez Abascal 2

28006 Madrid (Spain)

Tel: +34 914111328 ext 1111

Fax: +34 915645078

E-mail: cass@eeza.csic.es 


\begin{abstract}
A study carried out in four multi-male groups of captive dama gazelle (Gazella dama mhorr) characterized the social rank order of males and possible enclosure effects on aggression rate. A strong relationship between rank and age was found. The results also showed that dominant individuals in the two smallest enclosures were more aggressive than their herdmates, suggesting a more stressful environment which might precipitate unstable or challenged hierarchies when the animals live in a more restricted enclosure. Subordinate males performed a higher frequency of submissive responses, irrespective of the size of the enclosure. The frequency of interactions between the gazelles, on the other hand, was affected by enclosure size, since high-ranking males showed higher values than low-ranking males in the two smallest enclosures. Frequencies of aggressive acts, retreats and related interactions were similar in all the herds. Implications for the management of the species in captivity are discussed.
\end{abstract}

Key words: stress, ungulates, zoos 


\section{Introduction}

The management of endangered species in captivity must assure the welfare of the individuals and resemble as far as possible their natural conditions in the wild. It is known that keeping animals in restricted environments affects their normal behavior patterns [e.g. Markowitz, 1982; Wilson, 1982], and, if sufficiently small, the size of the enclosure can influence individual welfare and cause the appearance of stereotypic behaviors [see Draper and Bernstein, 1963; Odberg, 1987; cf. Lyons et al., 1997]. On the other hand, enclosure size and group size determine stocking density, which is one of the extrinsic factors that may influence reproductive success [Bailey, 1991]. Thus, e.g., Skiff [1982, in Boyd, 1991] found that Przewalski's horses individuals kept in a small enclosure (0.05 ha) showed a higher number of activities [see also Boyd, 1988] and rate of aggression than individuals kept on pasture (3.5 ha) [but see Boyd, 1991].

The study subspecies, Gazella dama mhorr Bennet 1833, is supposedly extinct in the wild since 1968, due to hunting; its general distribution included Southwest Morocco and Western Sahara. The species is categorized in the IUCN Red List of Threatened Animals [IUCN, 1996] as "Endangered". Fortunately, this subspecies has bred successfully since 1971 in the Estación Experimental de Zonas Aridas (EEZA), in Almería, Spain. Currently, 109 individuals can be found at the EEZA facilities, and approximately 180 have been distributed in different zoos around the world: in Europe (Frankfurt, Berlin, Munich, Belfast, Jerez de la Frontera and Barcelona), America (San Diego and Palm Desert), Asia (Al Ain) and Africa (Pretoria). Successful reintroductions in the wild have been carried out in Senegal (Guembeul Reserve), Tunisia (Bou-Hedma National Park) and Morocco (Sous-Massa National Park and R'Mila Reserve). The species 
is territorial and herds are organised under dominance hierarchies [Alados and Escós, 1992]; but, to our knowledge, no information on natural history of the species can be found in the literature.

Herein we have carried out the first analysis on social ranks in males of dama gazelle [the females' ranks were studied by Alados and Escós, 1992], and attempted to find relationships between social ranks, aggressive behavior, and characteristics of enclosures. The conservation value of this population is high, and proper captive management should be observed, individuals' welfare being a main part of it.

\section{Methods}

Data were collected from a captive population of dama gazelle from EEZA (see Introduction). The founder population consists of 3 males and 9 females. A complete database is available for all the individuals including date of birth, dam and sire identity, sex, body weight at birth, date of death and descendants' identity. Individuals are marked with ear tags at birth which facilitates individual recognition.

In this study four multi-male herds of dama gazelle (see Table 1) were observed for a period of 11 weeks (from 27th January to 19th March 1997). Each herd consisted of four males of similar age and was established more than six months before the sampling took place, so all the individuals were used to each other.

Table 1 near here 
A Psion Organiser II (Model XP) was utilized for data collection. Sampling was carried out every day from 17:00 to 19:00 $\mathrm{h}$, when the animals are more active. Each herd was sampled for ca. $1 \mathrm{~h}$ every other day. Herd monitoring (ad libitum sampling and continuous recording) was easy to perform as all the individuals were visible all the time [see Martin and Bateson, 1986]. Sampling was carried out by the same person (I.P.) and started several minutes after arrival. Aggression was behaviourally assessed by: horn display (one individual directs its horns towards another), horn contest (two or more individuals engage in horn fights, which may last several minutes) and butting (one individual punches another with its horns). All frequencies were measured as the number of events divided by the total observation time of each sampling period.

Social ranks were calculated by means of a matrix of submissive interactions; aggressive behavior by itself is not a reliable indicator of dominance status as it may sometimes be caused by stress or defensive responses [Craig, 1986]. Retreats were only noted when there was no doubt that the individuals responded to the approach and/or aggressive behavior of another individual [see Cassinello, 1995]. The dominance rank given to a particular individual corresponds to its status in the hierarchical order, in an increasing succession from 1 to 4 , where rank 1 is applied to the highest-ranking individual, and 4 to the lowest-ranking one. In order to undertake comparisons between rank and age, the latter was also distributed in classes, where age 1 corresponded to the oldest individual in each herd, and consequently 4 to the youngest one.

For comparative analyses between herds, the mean frequencies of behavioral variables in each herd were considered in order to prevent replication effects. ANOVAs and simple regression analyses have been 
used, and the usual transformations applied [Zar, 1984]: age was logtransformed and frequencies into the form $\sqrt{ }(x+0.5)$.

Results

Social ranks in male dama gazelles were stable during the period of the study, and showed a clear dependence on age $\left(n=16, r^{2}=0.71, p<0.0001\right)$, older individuals holding higher ranks (see Figure 1). Combining data from the four herds, aggression did not relate to social rank order $(\mathrm{F}(3,12)=1.75$, $\mathrm{p}=0.21$; Figure 2), but retreats were more frequent in subordinate individuals $(\mathrm{F}(3,12)=9.30, \mathrm{p}=0.002$; Figure 3$)$. Also, all of the herds presented similar values of aggressive $(\mathrm{F}(3,12)=1.82, \mathrm{p}=0.20)$ and submissive acts $(\mathrm{F}(3,12)=0.40, \mathrm{p}=0.75)$.

Figure 1 near here

Figure 2 near here

Figure 3 near here

Regarding the analysis of aggression in each herd, it was more frequent in dominant individuals living in the two smallest enclosures, i.e. herds 1 and 4 (see Figure 4). The frequency of retreats was similar when the data were analysed for each herd separately, i.e., high-ranking individuals had a lower frequency of submissive responses (see Figure 5). 
Figure 4 near here

Figure 5 near here

The frequency of interactions between individuals did not differ according to social rank $(\mathrm{F}(3,12)=1.69, \mathrm{p}=0.22)$; although from Figure 6 a tendency was appreciated and this frequency declined when males held lower ranks. Thus, by grouping ranks into two classes (high and lowranking individuals) it could be seen that dominant individuals (ranks 1 and 2: $\quad 0.75 \pm 0.006$ interactions/minute) interacted more frequently than subordinate ones (ranks 3 and 4: $0.73 \pm 0.005$ interactions/minute): $\mathrm{F}(1,14)=4.99, \mathrm{p}=0.04$. When considering individual herds, high-ranking males interacted more frequently than low-ranking ones only in the two smallest enclosures (see Table 1; Herd 1: $\mathrm{F}(1,66)=14.24$, $\mathrm{p}=0.0003$; Herd 2: $\quad \mathrm{F}(1,66)=0.14, \mathrm{p}=0.71$; Herd 3: $\mathrm{F}(1,66)=3.26, \mathrm{p}=0.08 ;$ Herd 4: $\mathrm{F}(1,66)=6.78, \mathrm{p}=0.01)$.

Figure 6 near here

Without taking social ranks into account, it appeared that frequencies of aggression $(\mathrm{F}(3,12)=1.82, \mathrm{p}=0.20)$, submissive behavior $(\mathrm{F}(3,12)=0.40, \mathrm{p}=0.75)$, and interactions $(\mathrm{F}(3,12)=1.75, \mathrm{p}=0.21)$ were 
similar in all herds. Finally, the frequency of aggression did not vary with age $(\mathrm{F}(3,12)=1.35, \mathrm{p}=0.30)$. Though there were no differences in the frequency of submissive responses when all age classes were compared $(\mathrm{F}(3,12)=2.48, \mathrm{p}=0.11)$, the Fisher's post-hoc test revealed that age class 1 individuals retreated significantly less than age class 4 individuals: $\mathrm{p}=0.02$.

\section{Discussion}

The relationship found between rank and age in male dama gazelles has already been observed in females of other ungulates [e.g. Rutberg, 1983; Alados and Escós, 1992; Thompson, 1993; Cassinello, 1995], but not in females of dama gazelle [Alados and Escós, 1992]. An explanation for that may be that social rank is challenged in female dama gazelles, and they are not a consequence of an early-in-life establishment [cf. Rutberg, 1983], that is, the hierarchical order might vary due to the fact that formerly subordinate individuals manage to get a higher social status [see Alados and Escós, 1992]. In bachelor or multi-male groups encompassing a sufficiently wide range of age (see Table 1), however, age seems to determine the social status of the individuals, in spite of the unstability suffered by the hierarchies during longer periods, as rank alternations have been registered in some herds observed throughout one year (J.C. pers.obs.). The species is territorial. Males do not gather in groups during the mating season; this must be taken into account not only during its management in captivity (herd structure and composition), but also when extrapolating data obtained under socially unnatural conditions.

In this study a relationship between rates of aggression and size of enclosure was found in captive male dama gazelles (when taking into consideration the social rank of the individual). Although enclosure sizes here are similar [cf. Skiff, 1982 in Boyd, 1991], significant differences 
emerged from the analyses of dominant gazelles, suggesting smaller enclosures provide a more stressful environment which might precipitate unstable or challenged hierarchies. The results obtained are in a way consistent with those of Skiff [ibid.], and although we have only considered interactive behaviors between individuals, and not stereotypies [see Mason, 1991], high-ranking gazelles show a higher frequency of interactions in the two smallest enclosures. We can argue whether this is a valid indication of stress, and although we have not carried out hormone analysis here, the presence of indirect clues, such as stereotypies (see below) and injuries due to fights, are common in the study population (J.C. pers.obs.); this type of injuries are probably caused by the fact that enclosure small sizes prevent males to escape from aggressive herdmates. Recently though, cortisol levels have been analysed in this gazelle population and the results obtained show a relationship between stress and social rank [Cassinello, Gomendio and Roldan, in prep.]. Finally, the relationship found between age and submissive responses reflects the clear one formerly seen between age and rank.

This should be considered as a first attempt which leads to the issue of the minimal proper size an enclosure must be so that captive animals do not develop an excess of aggression or stress due to the lack of sufficient space. Further studies should be carried out where enclosure size differs substantially. Going deeply into the implications of this kind of studies, population density, and therefore stocking density, may be considered as one of the extrinsic factors that influence reproductive success [Bailey, 1991]; and it has been seen that increasing densities decrease the age at first birth of females, one of the main factor which determine their reproductive success [see Pusenius and Viitala, 1993; Cassinello and Alados, 1996]. Another factor which should be considered when planning 
herds structure and disposition is the neighbour effect [Baker and Aureli, 1996]; a correct disposition of the enclosure, far from other herds made up of individuals of the same or different species, will prevent possible stressful responses due to threats executed through the fences, which cannot be replied. Finally, although no attempt to analyse stereotypies in relation to enclosure size has been done, they are frequent in the study population, particularly in isolated individuals (J.C. pers.obs.). In sum, further studies including stereotypic behaviors and measurements of stress should be carried out in order to get a better knowledge of the animals' welfare and suggest improvements in the management of the species.

\section{Conclusions}

1.- Social ranks in male dama gazelles are determined by age.

2.- Smaller enclosures are associated with a higher rate of aggression in high-ranking individuals.

3.- Smaller enclosures are associated with a higher rate of interactions between the individuals.

\section{Acknowledgements}

The authors wish to thank two anonymous reviewers for their useful comments on an earlier version of the manuscript. During data collection I.P. benefited from an Erasmus grant which allowed her to visit the EEZA. J.C. is currently supported by DGES Project PB96-0880. 


\section{References}

Alados CL, Escós JM. 1992. The determinants of social status and the effect of female rank on reproductive success in Dama and Cuvier's gazelles. Ethol Ecol Evol 4:151-164.

Bailey JA. 1991. Reproductive success in female mountain goats. Can J Zool 69:2956-2961.

Baker KC, Aureli F. 1996. The neighbor effect: other groups influence intragroup agonistic behavior in captive chimpanzees. Am J Primatol 40:283-291.

Boyd LE. 1988. Time budgets of adult Przewalski's horses: effects of sex, reproductive status, and enclosure. Appl Anim Behav Sci 21:19-39.

Boyd LE. 1991. The behavior of Przewalski's horses and its importance to their management. Appl Anim Behav Sci 29:301-318.

Cassinello J. 1995. Factors modifying female social ranks in Ammotragus. Appl Anim Behav Sci 45:175-180.

Cassinello J, Alados CL. 1996. Female reproductive success in captive Ammotragus lervia (Bovidae, Artiodactyla). Study of its components and effects of hierarchy and inbreeding. J Zool 239:141-153.

Craig JV . 1986. Measuring social behaviour: social dominance. J Anim Sci 62:1120-1129.

Draper WA, Bernstein IS. 1963. Stereotyped behavior and cage size. Perceptual and motor skills 16:231-234.

Lyons J, Young RJ, Deag JM. 1997. The effects of physical characteristics of the environment and feeding regime on the behavior of captive felids. Zoo Biol 16:71-83.

Markowitz H. 1982. Behavioral enrichment in the zoo. New York: Van Nostrand Reinhold. 
Martin P, Bateson P. 1986. Measuring behaviour. An introductory guide. Cambridge: Cambridge Univ. Press.

Mason G. 1991. Stereotypies: a critical review. Anim Behav 41:10151037.

Odberg FO. 1987. The influence of cage size and environmental enrichment on the development of stereotypies in bank voles (Clethrionmys glareolus). Behav Proces 14:155-173.

Pusenius J, Viitala J. 1993. Demography and regulation of the breeding density in the field vole, Microtus agrestis. Ann Zool Fen 30:133-142.

Rutberg AT. 1983. Factors influencing dominance status in American bison cows (Bison bison). Z Tierpsychol 63:206-212.

Thompson KV. 1993. Aggressive behaviour and dominance hierarchies in female sable antelope, Hippotragus niger: implications for captive management. Zoo Biol 12:189-202.

Wilson SF. 1982. Environmental influences on the activity of captive apes. Zoo Biol 1: 201-209.

Zar JH. 1984. Biostatistical analysis. 2nd edition, Englewood Cliffs, New Jersey: Prentice-Hall, Inc. 
Table 1. Characteristics of herds and individuals used in this study

\begin{tabular}{|c|c|c|c|c|c|}
\hline Herd & Dimensions $\left(\mathrm{m}^{2}\right)$ & Gazelle & Age (years) & Age group & Rank position \\
\hline 1 & 162 & 811 & 1.498 & 1 & 1 \\
\hline 1 & 162 & 848 & 1.262 & 2 & 2 \\
\hline 1 & 162 & 849 & 1.254 & 3 & 3 \\
\hline 1 & 162 & 851 & 1.207 & 4 & 4 \\
\hline 2 & 223 & 794 & 2.160 & 1 & 1 \\
\hline 2 & 223 & 796 & 2.152 & 2 & 3 \\
\hline 2 & 223 & 797 & 2.146 & 3 & 2 \\
\hline 2 & 223 & 802 & 2.064 & 4 & 4 \\
\hline 3 & 240 & 727 & 3.869 & 1 & 1 \\
\hline 3 & 240 & 728 & 3.803 & 2 & 2 \\
\hline 3 & 240 & 735 & 3.518 & 3 & 4 \\
\hline 3 & 240 & 738 & 3.379 & 4 & 3 \\
\hline 4 & 210 & 282 & 12.014 & 1 & 2 \\
\hline 4 & 210 & 372 & 10.103 & 2 & 1 \\
\hline 4 & 210 & 374 & 10.018 & 3 & 3 \\
\hline 4 & 210 & 388 & 9.188 & 4 & 4 \\
\hline
\end{tabular}




\section{Legends}

Figure 1. Relationship between age class and rank in male dama gazelles. Log-transformation has been applied.

Figure 2. Mean (+SE) frequency of aggression (aggressions/minute) according to the individuals' social rank (1-4) in male dama gazelles. The number of cases is 4 .

Figure 3. Mean (+SE) frequency of retreats (retreats/minute) according to the individuals' social rank (1-4) in male dama gazelles. The number of cases is 4 . Fisher's post-hoc test shows that rank 1 is significantly different from the others $(\mathrm{p} \leq 0.04)$ and rank 2 from rank $4(\mathrm{p}=0.02)$.

Figure 4. Mean (+SE) frequency of aggression (aggressions/minute) according to the individuals' social rank (1-4) in four multi-male herds of dama gazelles. The number of cases is 17. ANOVA outputs: Herd 1: $\mathrm{F}(3,64)=4.78, \mathrm{p}=0.004$; Herd 2: $\mathrm{F}(3,64)=1.02, \mathrm{p}=0.39$; Herd 3: $F(3,64)=1.42, p=0.24 ;$ Herd $4: F(3,64)=3.89, p=0.01$. Fisher's post hoc test shows significant differences between the following ranks: Herd 1: 1-3 $(\mathrm{p}=0.01), 1-4(\mathrm{p}=0.002)$ and 2-4 $(\mathrm{p}=0.01) ;$ Herd $4: 1-4(\mathrm{p}=0.003)$ and 2-4 $(\mathrm{p}=0.01)$.

Figure 5. Mean (+SE) frequency of retreats (retreats/minute) according to the individuals' social rank (1-4) in four multi-male herds of dama gazelles. The number of cases is 17. ANOVA outputs: Herd 1: $F(3,64)=4.84$, $\mathrm{p}=0.004$; Herd 2: $\mathrm{F}(3,64)=14.25, \mathrm{p}<0.0001 ;$ Herd 3: $\mathrm{F}(3,64)=5.38$, $p=0.002 ;$ Herd 4: $F(3,64)=6.49, p=0.0007$. Fisher's post hoc test shows significant differences between the following ranks: Herd 1: rank 1 different from the others ( $\mathrm{p} \leq 0.009)$; Herd 2: ranks 1, 2 different from 3, 4 ( $\mathrm{p} \leq 0.003)$; Herd 3: rank 4 different from the others ( $\mathrm{p} \leq 0.003)$; Herd 4: rank 1 different from $3,4(\mathrm{p} \leq 0.0009)$ and rank 2 different from $3(\mathrm{p}=0.03)$. 
15 Cassinello \& Pieters

Figure 6. Mean $( \pm \mathrm{SE})$ frequency of interactions (interactions/minute) according to the individuals' social rank (1-4) in male dama gazelles. The number of cases is 4 . 




FIGURE 1 - CASSINELLO and PIETERS 


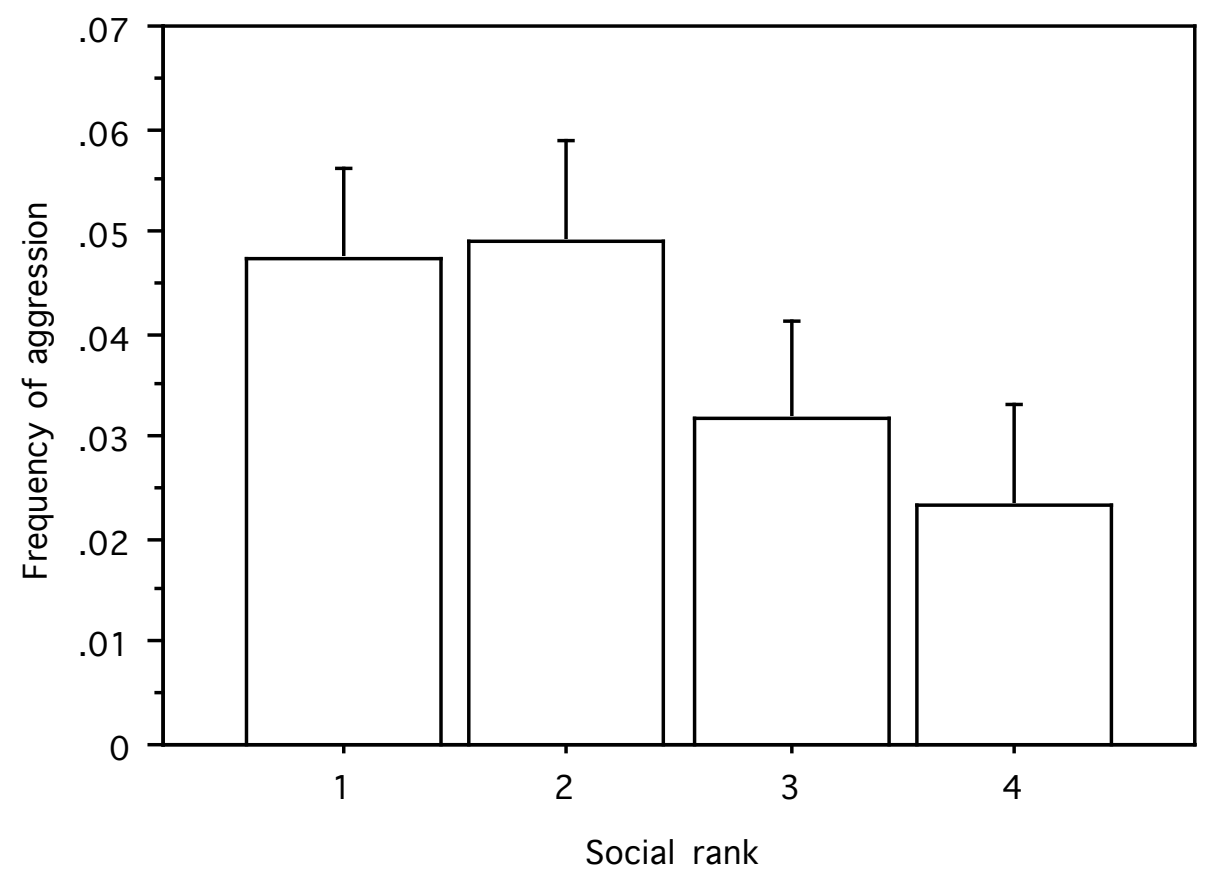

FIGURE 2 - CASSINELLO and PIETERS 




FIGURE 3 - CASSINELLO and PIETERS 

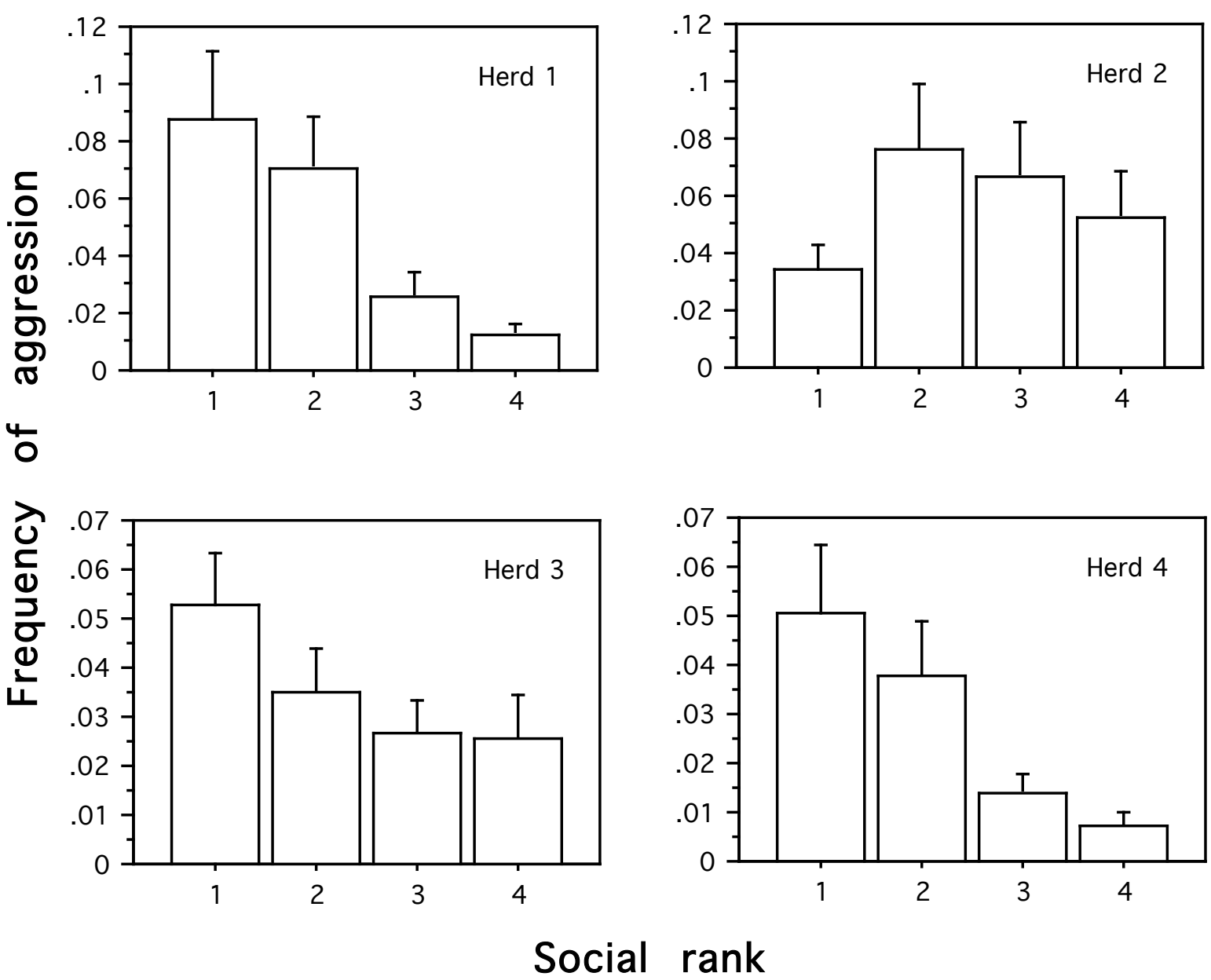

FIGURE 4 - CASSINELLO and PIETERS 

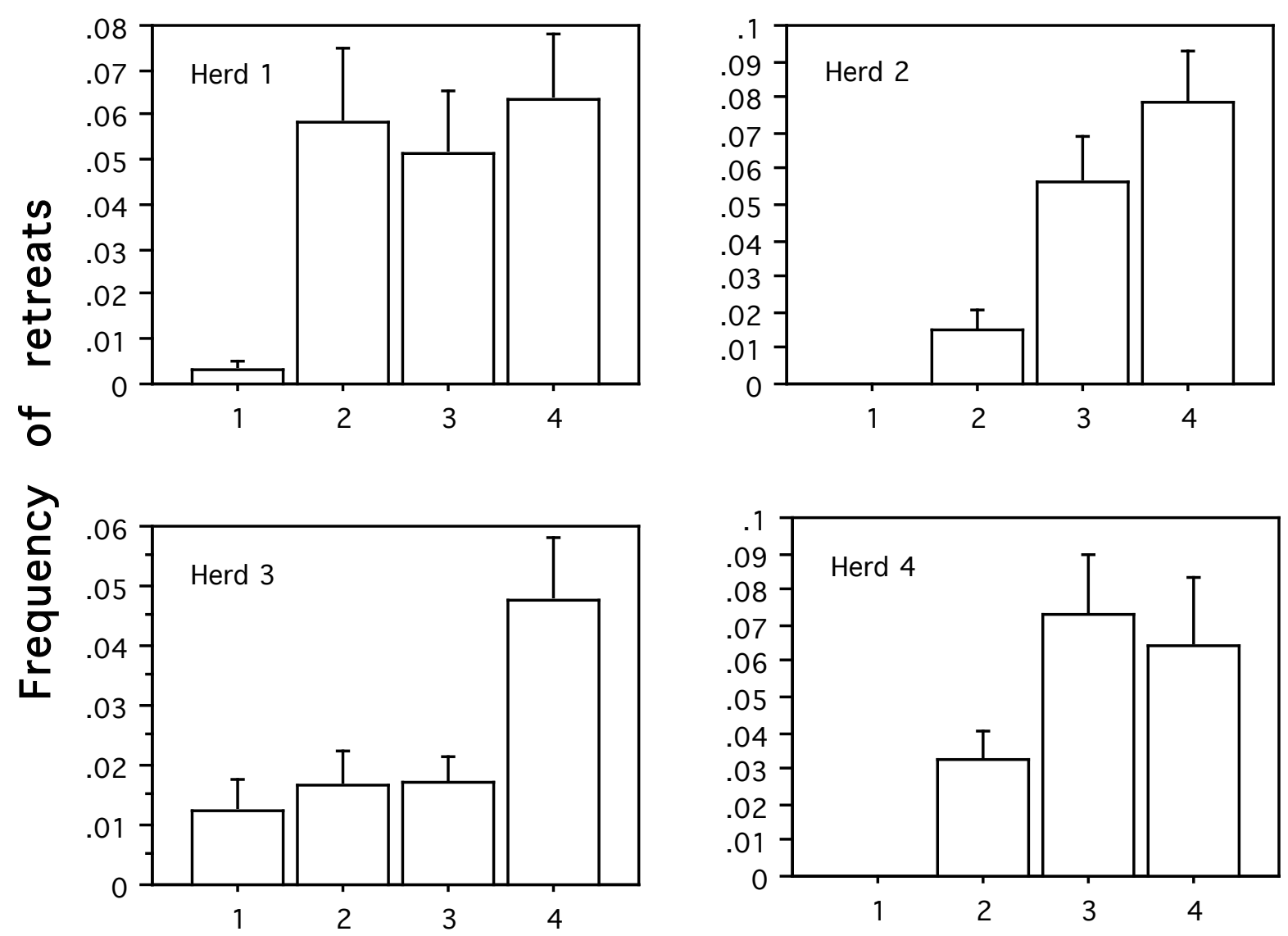

Social rank

FIGURE 5 - CASSINELLO and PIETERS 




FIGURE 6 - CASSINELLO and PIETERS 